\title{
Cerebral blood flow velocity in migraine and chronic tension-type headache patients
}

This article was published in the following Dove Press journal: Journal of Pain Research

\author{
S Karacay Ozkalayci \\ B Nazliel \\ HZ Batur Caglayan \\ C Irkec \\ Department of Neurology, Faculty \\ of Medicine, Gazi University, Ankara, \\ Turkey
}

\begin{abstract}
Introduction: The present study seeks to use transcranial Doppler ultrasound to evaluate cerebral blood flow velocities in anterior and posterior circulation arteries, during an attack-free episode in migraine patients, with and without aura, as well as in chronic tension-type headache patients who were not receiving prophylactic medication.
\end{abstract}

Methods: A total of 50 patients (35 female, 15 male) were evaluated during a headache-free episode: 30 migraine patients without aura (mean age: $32 \pm 8$ years), 10 migraine patients with aura (mean age: $34 \pm 4$ years), and 10 patients with chronic tension-type headache (mean age: $34 \pm 5$ years). Results: No significant difference was present between anterior, middle, and posterior cerebral and vertebral arteries' blood flow velocities between migraine patients, with and without aura, or in patients with a tension-type headache, and normal controls $(p>0.05)$. However, a significant increase in basilar artery cerebral blood flow velocities relative to controls was present in patients with a tension-type headache ( $p>0.001)$.

Conclusion: It is difficult to predict the main reason for the significant increase in basilar artery blood flow velocities in patients with chronic tension-type headache. It may be due to constriction of conductance or the dilatation of the resistance vessels.

Keywords: cerebral blood flow, migraine without aura, migraine with aura, tension-type headache, transcranial Doppler ultrasonography

\section{Introduction}

Although the development of migraine is believed to be mainly neurogenic, vascular changes also have a basic role in migraine pathophysiology. Studies performed on migraine patients during attack or attack-free episodes have reported abnormalities in hemodynamics. ${ }^{1-12}$ In four studies, Drummond, Gannon and Haynes emphasized the power of vascular factors in tension-type headaches. ${ }^{13-16}$ Transcranial Doppler ultrasound (TCD), although not as sensitive as positron emission tomography or single-photon emission computed tomography, permits the noninvasive measurement of blood flow velocities in basal brain arteries. ${ }^{17}$

The aim of the present study is to evaluate cerebral blood flow (CBF) velocities using TCD during an attack-free episode in anterior cerebral, middle cerebral, and posterior cerebral arteries in migraine patients with and without aura as well as in chronic tension-type headache patients who were not receiving prophylactic medication for their headaches.

\section{Materials and methods}

This study was reviewed and approved by the Local Ethics Committee of Gazi University Faculty of Medicine. The study protocol was in accordance with the Declaration 
of Helsinki, and all volunteers gave written informed consent before participating in the study. A total of 50 patients (35 F, $15 \mathrm{M}$ ) were evaluated during a headache-free episode: 30 migraine patients without aura (mean age: $32 \pm 8$ years), 10 migraine patients with aura (mean age: $34 \pm 4$ ), and 10 patients with chronic tension-type headache (mean age: $34 \pm 5$ ).

All patients fulfilled the diagnostic criteria for migraine and chronic tension-type headaches established in the International Headache Society's International Classification of Headache Disorders, second edition. ${ }^{18}$ Each patient had a normal neurological examination. Patients with psychiatric diseases, diabetes mellitus, epilepsy, cardiovascular disorders, cerebrovascular disease, or with known systemic diseases such as anemia and hypertension were excluded. All patients were examined during a headache-free episode and at least 72 hours after the last headache attack. None of the patients were receiving prophylactic medication for headache or any treatment known to affect CBF. Intake of analgesics, smoking, and consumption of caffeine were forbidden on the day of testing.

The age and sex were matched $(17 \mathrm{~F}, 8 \mathrm{M})$ in healthy volunteers (mean age: $31 \pm 8$ ) who served as controls.

The study was performed in a quiet room with the subjects lying in a comfortable supine position. All Doppler recordings were performed by two operators who were blinded to the clinical status of the subjects. Intracranial arteries were insonated through the temporal and transforaminal windows using standardized protocol. Sample volume was 8-10 mm in the axial and $5 \mathrm{~mm}$ in the lateral direction at a depth of 50 $\mathrm{mm} .{ }^{19}$ Mean (Vm) and peak systolic (Vpeak-VP) velocities of middle cerebral artery (MCA) flow were recorded at depths of 50-60 mm, anterior cerebral artery (ACA) at 50-65 mm, posterior cerebral artery (PCA) at 55-65 mm, vertebral artery
(VA) at 50-70 $\mathrm{mm}$, and basilar artery (BA) at 80-100 $\mathrm{mm}$ with a 2-MHz probe by the technique described by Aaslid. ${ }^{19,20}$ Mean $(\mathrm{Vm})$ and peak systolic (Vpeak-VP) CBF velocities $(\mathrm{cm} / \mathrm{s})$ and pulsatility index (PI) were determined. Gosling's PI was calculated as the difference between $\mathrm{V}_{\max }$ and $\mathrm{V}_{\min }$, divided by the mean velocity. ${ }^{20}$ Only measurements with the best signal-tonoise ratio were used, and the highest values for CBF velocities were selected for analysis. All TCD studies were performed with the use of commercially available TCD apparatus, Viasys/ Sonara (Cardinal Health, Madison, WI, USA).

\section{Statistical evaluation}

The SPSS 15.0 package (SPSS Inc., Chicago, IL, USA) was used to perform the statistical evaluation. Chi-square, Wilcoxon, and Kruskal-Wallis tests were used for analysis. Mann-Whitney $U$-test with Bonferroni correction was utilized for two-to-two comparisons when a difference was found to be present with Kruskal-Wallis test. For correlation analysis, Kendall's tau test was utilized. Data were expressed as the mean $\pm \mathrm{SD}$, median ( $\min -\max )$. A level of $p<0.05$ was accepted as statistically significant.

\section{Results}

Duration of disease was between 2 and 20 years in patients with migraine and $2-15$ years in patients with tension-type headache. Headache characteristics of patients are presented in Table 1.

There were no significant differences between the measurements of the right and left arms of the arteries, so the data were pooled for further analysis $(p>0.05)$.

There were no significant differences between $\mathrm{CBF}$ velocities from the headache-affected side and the unaffected side $(p>0.05)$. CBF velocities of patients in anterior and posterior

Table I Age, disease duration, number of attacks, and duration of attacks in patients with migraine with and without aura and tensiontype headache

\begin{tabular}{|c|c|c|c|c|c|}
\hline Characteristics & Migraine with aura & Migraine without aura & Tension-type headache & Controls & $p$-value \\
\hline Age, years & $28-43(34 \pm 4)$ & $19-48(32 \pm 8)$ & $28-46(34 \pm 5)$ & $25-58(3 \mathrm{I} \pm 8)$ & \\
\hline \multicolumn{6}{|c|}{ Duration of disease, years } \\
\hline$<5$ & I & 7 & 2 & & 0.291 \\
\hline $5-10$ & 2 & 9 & 4 & & \\
\hline $10-15$ & 5 & 7 & 4 & & \\
\hline $15-20$ & 2 & 7 & - & & \\
\hline \multicolumn{6}{|c|}{ Number of attacks per month } \\
\hline$<4$ & 10 & 18 & - & & \\
\hline $5-10$ & - & 12 & - & & 0.000 \\
\hline$>10$ & - & - & 10 & & \\
\hline \multicolumn{6}{|l|}{ Duration of attacks } \\
\hline 4-24 hours & 6 & 24 & 10 & & 0.082 \\
\hline 24-72 hours & 4 & 6 & - & & \\
\hline
\end{tabular}

Note: Bold represents statistically significant value $(p<0.05)$. 
circulation arteries are presented in Tables 2 and 3. No significant differences were present between ACA, MCA, PCA, and VA's mean and peak systolic $\mathrm{CBF}$ velocities and $\mathrm{PI}$, between migraine patients with and without aura, as well as between patients with tension-type headache and normal controls ( $p>0.05)$.

However, a statistically significant difference in basilar arteries' mean and peak systolic velocities was present between groups $(p<0.05)$. To determine the source of difference, two-to-two comparisons were performed. A difference was present between tension-type headache participants and the control group ( $p>0.001)$, showing higher CBF velocities in patients with tension-type headache. No statistically significant difference in BA blood flow velocities was present between migraine patients with and without aura as well as those of normal controls (Table 3).

No correlation was present between CBF velocities and duration of disease, frequency, and duration of attacks $(p>0.05)$.

\section{Discussion}

Migraine is delineated by an extreme response of intracranial resistance vessels to metabolic stimulus. ${ }^{21}$ TCD is a noninvasive technique that evaluates the velocity, direction, and other properties of blood flow in the cerebral arteries, as well as the cerebrovascular reserve, using a pulsed ultrasonic beam. The flow velocities measured with TCD are directly proportional to invasive flow measurements. ${ }^{20,22}$

However, TCD studies in migraine have contradictory results. Studies conducted during attack-free episodes have shown either increased ${ }^{3,4,23-26}$ or normal blood flow velocities in migraine patients. ${ }^{27-29}$ Frieberg reported reduced $\mathrm{CBF}$ velocities in MCA on the headache side during a migraine attack when compared to the non-headache side and which was acquired during an attack-free episode, ${ }^{30}$ while Zwetsloot reported no velocity changes at the headache and non-headache side MCAs during an acute attack. ${ }^{28}$ It is argued that the increased flow velocity displayed by TCD is a hallmark of migraine. If so, it may be assumed or interpreted as due to an increase in CBF because of a decrease in the cross-sectional area of a vessel at or near the point of insonation or due to regional CBF changes at the level of arterioles. ${ }^{24}$ However, researchers have stated that TCD alone cannot specify which of these processes is responsible. ${ }^{24,28}$ In our study, we found no significant velocity differences in migraine patients with and without aura during a headachefree episode when compared to controls and to each other.

Wallasch reported increased $\mathrm{CBF}$ velocities in the $\mathrm{MCA}$, ACA, and PCA as well as decreased PI in patients with

Table 2 CBFVs in anterior circulation arteries

\begin{tabular}{|c|c|c|c|c|c|}
\hline & Group & $\mathbf{N}$ & Median & Mean \pm SD & $p$-value \\
\hline \multirow[t]{4}{*}{ MCA (mean) CBFV (cm/s) } & Migraine with aura & 10 & 67.50 & $66.77 \pm 8.64$ & $0.21 * *$ \\
\hline & Migraine without aura & 30 & 66.75 & $66.52 \pm 9.71$ & \\
\hline & Tension-type headache & 10 & 72.00 & $67.07 \pm 15.58$ & \\
\hline & Control & & 57.50 & $61.40 \pm 11.97$ & \\
\hline \multirow[t]{4}{*}{ MCA (peak) CBFV (cm/s) } & Migraine with aura & 10 & 110.00 & $113 \pm 25.6$ & $0.50 * *$ \\
\hline & Migraine without aura & 30 & 101.00 & $106.08 \pm 18.02$ & \\
\hline & Tension-type headache & 10 & 109.25 & $104.95 \pm 22.30$ & \\
\hline & Control & 25 & 93.50 & $102.03 \pm 24.90$ & \\
\hline \multirow[t]{4}{*}{ MCA PI } & Migraine with aura & 10 & 1.05 & $1.08 \pm 0.24$ & $0.90 * *$ \\
\hline & Migraine without aura & 30 & 0.97 & $1.03 \pm 0.19$ & \\
\hline & Tension-type headache & 10 & 1.02 & $1.03 \pm 0.16$ & \\
\hline & Control & 25 & 1.05 & $1.03 \pm 0.18$ & \\
\hline \multirow[t]{4}{*}{$\mathrm{ACA}$ (mean) $\mathrm{CBFV}(\mathrm{cm} / \mathrm{s})$} & Migraine with aura & 10 & 52.62 & $56.1 \pm 7.72$ & $0.38 * *$ \\
\hline & Migraine without aura & 30 & 46.50 & $47.88 \pm 7.38$ & \\
\hline & Tension-type headache & 10 & 48.75 & $49.80 \pm 11 ., 33$ & \\
\hline & Control & 25 & 47.50 & $48.7 I \pm 8.50$ & \\
\hline \multirow[t]{4}{*}{ ACA (peak) CBFV (cm/s) } & Migraine with aura & 10 & 81.50 & $77.02 \pm 11.91$ & $0.48 * *$ \\
\hline & Migraine without aura & 30 & 73.75 & $74.01 \pm 9.12$ & \\
\hline & Tension-type headache & 10 & 78.00 & $77.72 \pm 16.07$ & \\
\hline & Control & 25 & 76.25 & $78.11 \pm 10.82$ & \\
\hline \multirow[t]{4}{*}{ ACA PI } & Migraine with aura & 10 & 0.85 & $0.89 \pm 0.14$ & $0.26 * *$ \\
\hline & Migraine without aura & 30 & 0.97 & $1.02 \pm 0.21$ & \\
\hline & Tension-type headache & 10 & 0.97 & $0.97 \pm 0.12$ & \\
\hline & Control & 25 & 1.00 & $1.02 \pm 0.18$ & \\
\hline
\end{tabular}

Notes: **Mann-Whitney U-test with Bonferroni correction was utilized for two-to-two comparisons when a difference was found to be present with Kruskal-Wallis. Abbreviations: ACA, anterior cerebral artery; CBFV, cerebral blood flow velocity; MCA, middle cerebral artery; PI, pulsatility index. 
Table 3 CBFVs in posterior circulation arteries

\begin{tabular}{|c|c|c|c|c|c|}
\hline & Group & $\mathbf{N}$ & Median & Mean \pm SD & p-value \\
\hline \multirow[t]{4}{*}{ PCA (mean) CBFV $(\mathrm{cm} / \mathrm{s})$} & Migraine with aura & 10 & 25.00 & $25.27 \pm 2.89$ & $0.78 * *$ \\
\hline & Migraine without aura & 30 & 24.50 & $25.45 \pm 3.04$ & \\
\hline & Tension-type headache & 10 & 24.75 & $24.62 \pm 2.49$ & \\
\hline & Control & 25 & 24.50 & $24.06 \pm 2.77$ & \\
\hline \multirow[t]{4}{*}{ PSA (peak) CBFV (cm/s) } & Migraine with aura & 10 & 47.37 & $53.82 \pm 22.05$ & $0.38 * *$ \\
\hline & Migraine without aura & 30 & 52.75 & $54.09 \pm 17.05$ & \\
\hline & Tension-type headache & 10 & 43.50 & $45.00 \pm 6.91$ & \\
\hline & Control & 25 & 41.62 & $46.37 \pm 11.82$ & \\
\hline \multirow[t]{4}{*}{ PCA PI } & Migraine with aura & 10 & 1.25 & $1.56 \pm 0.84$ & $0.63 * *$ \\
\hline & Migraine without aura & 30 & 1.42 & $1.6 \mathrm{I} \pm 0.74$ & \\
\hline & Tension-type headache & 10 & 1.27 & $1.35 \pm 0.30$ & \\
\hline & Control & 25 & 1.35 & $1.37 \pm 0.48$ & \\
\hline \multirow[t]{4}{*}{ VA (mean) CBFV (cm/s) } & Migraine with aura & 10 & 34.62 & $38.47 \pm 8.76$ & $0.11 * *$ \\
\hline & Migraine without aura & 30 & 38.75 & $37.95 \pm 6.20$ & \\
\hline & Tension-type headache & 10 & 39.87 & $40.45 \pm 6.75$ & \\
\hline & Control & 25 & 32.50 & $34.33 \pm 6.93$ & \\
\hline \multirow[t]{4}{*}{ VA (peak) CBFV (cm/s) } & Migraine with aura & 10 & 56.62 & $60.07 \pm 13.13$ & $0.20 * *$ \\
\hline & Migraine without aura & 30 & 58.50 & $58.13 \pm 9.05$ & \\
\hline & Tension-type headache & 10 & 61.12 & $60.57 \pm 7.31$ & \\
\hline & Control & 25 & 52.37 & $53.58 \pm 10.49$ & \\
\hline \multirow[t]{4}{*}{ VA PI } & Migraine with aura & 10 & 1.07 & $1.11 \pm 0.18$ & $0.24 * *$ \\
\hline & Migraine without aura & 30 & 0.97 & $1.01 \pm 0.20$ & \\
\hline & Tension-type headache & 10 & 1.00 & $0.96 \pm 0.14$ & \\
\hline & Control & 25 & 0.95 & $0.96 \pm 0.16$ & \\
\hline \multirow[t]{4}{*}{$\mathrm{BA}($ mean) $\mathrm{CBFV}(\mathrm{cm} / \mathrm{s})$} & Migraine with aura & 10 & 48.00 & $46.80 \pm 14.06$ & $0.001 * *$ \\
\hline & Migraine without aura & 30 & 44.50 & $43.96 \pm 9.48$ & \\
\hline & Tension-type headache & 10 & 55.00 & $57.88 \pm 7.75$ & \\
\hline & Control & 25 & 42.00 & $40.48 \pm 8.36$ & \\
\hline \multirow[t]{4}{*}{ BA (peak) CBFV $(\mathrm{cm} / \mathrm{s})$} & Migraine with aura & 10 & 83.00 & $82.90 \pm 16.56$ & $0.001 * *$ \\
\hline & Migraine without aura & 30 & 70.25 & $71.4 I \pm 14.92$ & \\
\hline & Tension-type headache & 10 & 88.00 & $88.33 \pm 8.87$ & \\
\hline & Control & 25 & 65.00 & $66.42 \pm 16.25$ & \\
\hline \multirow[t]{4}{*}{ BA PI } & Migraine with aura & 10 & 1.20 & $1.26 \pm 0.38$ & $0.17 * *$ \\
\hline & Migraine without aura & 30 & 1.00 & $1.12 \pm 0.40$ & \\
\hline & Tension-type headache & 10 & 0.90 & $0.98 \pm 0.23$ & \\
\hline & Control & 25 & 0.90 & $1.03 \pm 0.28$ & \\
\hline
\end{tabular}

Notes: **Mann-Whitney $U$ with Bonferroni correction was utilized for two-to-two comparisons when a difference was found to be present with Kruskal-Wallis test. Bold represents statistically significant values $(p<0.05)$.

Abbreviations: BA, basilar artery; CBFV, cerebral blood flow velocity; PCA, posterior cerebral artery; PI, pulsatility index; VA, vertebral artery.

episodic tension-type headache, while no difference was present in patients with chronic tension-type headache. ${ }^{31} \mathrm{In}$ the present study, we found increased BA CBF velocities in patients with chronic tension-type headache, and no difference was present in other examined arteries.

Variable outcomes present in the schedule and properties of flow fluctuations in different kinds of headaches make it challenging to understand the precise role of vascular changes in these settings. ${ }^{27} \mathrm{TCD}$ monitored changes in cerebral blood volume (CBV) have also been shown to correlate with changes in global CBF, and measurements were made using the Xenon washout technique. Changes in CBF have been shown to correlate with flow only if MCA diameter at the point of insonation does not change. As a matter of course, changes in large or small vessel diameter or in arterial blood pressure exceeding the range of autoregulation can qualify CBV values. ${ }^{32}$

In the present study, we only evaluated patients who had been attack free for the preceding 72 hours and were not receiving prophylactic medication. No statistically significant difference was found in $\mathrm{CBF}$ velocities between the migraine and normal control groups. Furthermore, mean $(\mathrm{Vm})$ and peak systolic (Vpeak-VP) velocities, and PIs of ACA and MCA showed no significant differences. Mean $(\mathrm{Vm})$ and peak systolic (Vpeak-VP) velocities of BA were increased in patients with tension-type headache. These changes can be explained by the vasodilator activity of neurotransmitters such as nitric oxide (NO) and calcitonin gene-related peptide, 
contributing to central sensitization. It may also be due to constriction of conductance or the dilatation of the resistance vessels. ${ }^{33}$ On the other hand, the lack of changes in CBF velocities in migraine indicates that the neuronal activation is more prominent than vascular effects.

\section{Limitations of the study}

The local ethics committee only allowed us a limited time period to complete the study; we could not include more patients after this allocated time. During that period, we could only evaluate 10 patients with chronic tension-type headache because it is difficult to find patients with tensiontype headaches who do not receive prophylactic medication. Even though the subgroups were small, the operators were blinded to the patients' clinical status.

Although we had a control group composed of healthy volunteers, we could not form a control group including patients with secondary headaches.

\section{Acknowledgment}

This clinical study was presented as a preliminary report at the 66th AAN (American Academy of Neurology) Annual Meeting in Philadelphia, Pennsylvania-April 26-May 3, 2014 (P7.181).

\section{Disclosure}

The authors report no conflicts of interest in this work.

\section{References}

1. Silvestrini M, Cupini LM, Troisi E, Matteis M, Bernardi G. Estimation of cerebrovascular reactivity in migraine without aura. Stroke. 1995;26(1):81-83.

2. Fiermonte G, Annulli A, Pierelli F. Transcranial Doppler evaluation of cerebral hemodynamics in migraineurs during prophylactic treatment with flunarizine. Cephalalgia. 1999;19(5):492-496.

3. Thie A, Spitzer K, Lachenmayer L, Kunze K. Prolonged vasospasm in migraine detected by noninvasive transcranial Doppler ultrasound. Headache. 1988;28(3):183-186.

4. Totaro R, De Matteis G, Marini C, Prencipe M. Cerebral blood flow in migraine with aura: a transcranial Doppler sonography study. Headache. 1992;32(9):446-451.

5. Zwetsloot CP, Caekebeke JF, Jansen JC, Odink J, Ferrari MD. Blood flow velocity changes in migraine attacks--a transcranial Doppler study. Cephalalgia. 1991;11(2):103-107.

6. De Benedittis G, Ferrari Da Passano C, Granata G, Lorenzetti A. CBF changes during headache-free periods and spontaneous/induced attacks in migraine with and without aura: a TCD and SPECT comparison study. J Neurosurg Sci. 1999;43(2):141-146; discussion 146-147.

7. Lauritzen M, Olesen J. Regional cerebral blood flow during migraine attacks by Xenon-133 inhalation and emission tomography. Brain. 1984;107 (Pt 2):447-461.

8. Harer C, von Kummer R. Cerebrovascular $\mathrm{CO} 2$ reactivity in migraine: assessment by transcranial Doppler ultrasound. J Neurol. 1991;238(1):23-26.

9. Skyhoj Olsen T, Lassen NA. Blood flow and vascular reactivity during attacks of classic migraine--limitations of the Xe-133 intraarterial technique. Headache. 1989;29(1):15-20.
10. Totaro R, Marini C, De Matteis G, Di Napoli M, Carolei A. Cerebrovascular reactivity in migraine during headache-free intervals. Cephalalgia. 1997;17(3):191-194.

11. Thomas TD, Harpold GJ, Troost BT. Cerebrovascular reactivity in migraineurs as measured by transcranial Doppler. Cephalalgia. 1990;10(2):95-99.

12. Dora B, Balkan S, Tercan E. Normalization of high interictal cerebrovascular reactivity in migraine without aura by treatment with flunarizine. Headache. 2003;43(5):464-469.

13. Drummond PD, Lance JW. Extracranial vascular reactivity in migraine and tension headache. Cephalalgia. 1981;1(3):149-155.

14. Gannon LR, Haynes SN, Cuevas J, Chavez R. Psychophysiological correlates of induced headaches. J Behav Med. 1987;10(4):411-423.

15. Haynes SN, Cuevas J, Gannon LR. The psychophysiological etiology of muscle-contraction headache. Headache. 1982;22(3):122-132.

16. Haynes SN, Gannon LR, Bank J, Shelton D, Goodwin J. Cephalic blood flow correlates of induced headaches. JBehav Med. 1990;13(5):467-480.

17. Rosengarten B, Huwendiek O, Kaps M. Neurovascular coupling in terms of a control system: validation of a second-order linear system model. Ultrasound Med Biol. 2001;27(5):631-635.

18. Headache Classification Subcommittee of the International Headache S. The International Classification of Headache Disorders. 2nd ed. Cephalalgia. 2004;24(Suppl 1):9-160.

19. Nazliel B, Irkec C, BaturCaglayan H, Capraz Yildirim I, Akkaya E, Kenan I. Correlation of Cerebral Blood Flow Velocities and Event-related Potentials in Patients with MS. J Neurol Neurophysiol 2014;5(3):198.

20. Aaslid R, Markwalder TM, Nornes H. Noninvasive transcranial Doppler ultrasound recording of flow velocity in basal cerebral arteries. J Neurosurg. 1982;57(6):769-774.

21. Wallasch TM, Beckmann P, Kropp P. Cerebrovascular reactivity during the Valsalva maneuver in migraine, tension-type headache and medication overuse headache. Funct Neurol. 2011;26(4):223-227.

22. Fodale V, Schifilliti D, Conti A, Lucanto T, Pino G, Santamaria LB. Transcranial Doppler and anesthetics. Acta Anaesthesiol Scand. 2007;51(7):839-847.

23. Valikovics A, Olah L, Fulesdi B, et al. Cerebrovascular reactivity measured by transcranial Doppler in migraine. Headache. 1996;36(5): 323-328.

24. Kastrup A, Thomas C, Hartmann C, Schabet M. Cerebral blood flow and $\mathrm{CO} 2$ reactivity in interictal migraineurs: a transcranial Doppler study. Headache. 1998;38(8):608-613.

25. Abernathy M, Donnelly G, Kay G, et al. Transcranial Doppler sonography in headache-free migraineurs. Headache. 1994;34(4): 198-203.

26. Thie A, Fuhlendorf A, Spitzer K, Kunze K. Transcranial Doppler evaluation of common and classic migraine. Part I. Ultrasonic features during the headache-free period. Headache. 1990;30(4):201-208.

27. Silvestrini M, Matteis M, Troisi E, Cupini LM, Bernardi G. Cerebrovascular reactivity in migraine with and without aura. Headache. 1996;36(1):37-40.

28. Zwetsloot CP, Caekebeke JF, Ferrari MD. Lack of asymmetry of middle cerebral artery blood velocity in unilateral migraine. Stroke. 1993;24(9):1335-1338.

29. Dora B, Balkan S. Exaggerated interictal cerebrovascular reactivity but normal blood flow velocities in migraine without aura. Cephalalgia. 2002;22(4):288-290.

30. Friberg L, Olesen J, Iversen HK, Sperling B. Migraine pain associated with middle cerebral artery dilatation: reversal by sumatriptan. Lancet. 1991;338(8758):13-17.

31. Wallasch TM. Transcranial Doppler ultrasonic features in episodic tension-type headache. Cephalalgia. 1992;12(5):293-296.

32. Micieli G, Bosone D, Marcheselli S, Cavallini A, Rossi F, Nappi G. Cerebral hemodynamics in primary headaches: the transcranial Doppler experience. Cephalalgia. 1998;18(Suppl 21):17-22.

33. Ashina M. Neurobiology of chronic tension-type headache. Cephalalgia. 2004;24(3):161-172. 
The Journal of Pain Research is an international, peer reviewed, open access, online journal that welcomes laboratory and clinical findings in the fields of pain research and the prevention and management of pain. Original research, reviews, symposium reports, hypothesis formation and commentaries are all considered for publication.

Submit your manuscript here: https://www.dovepress.com/journal-of-pain-research-journal

The manuscript management system is completely online and includes a very quick and fair peer-review system, which is all easy to use. Visit http://www.dovepress.com/testimonials.php to read real quotes from published authors. 